\title{
WELL-POSEDNESS AND GENERAL ENERGY DECAY OF SOLUTIONS FOR A PETROVSKY EQUATION WITH A NONLINEAR STRONG DISSIPATION
}

TAYEB LAKROUMBE, MAMA ABDELLI, NAIMA LOUHIBI, and MOUNIR BAHLIL

\begin{abstract}
In this paper we consider a nonlinear Petrovsky equation in a bounded domain with a strong dissipation

$$
u^{\prime \prime}+\Delta^{2} u-g\left(\Delta u^{\prime}\right)=0 .
$$

and prove the existence and the uniqueness of the solution using the energy method combined with the Faedo-Galerkin procedure under certain assumptions for $g$. Furthermore, we study the asymptotic behaviour of the solutions using a perturbed energy method.
\end{abstract}

MSC 2010. 35B40, 35B45, 35L70.

Key words. Well-posedness, general decay, multiplier method, convexity, Petrovsky equation.

\section{REFERENCES}

[1] R.A. Adams, Sobolev spaces, Pure and Applied Mathematics, Vol. 65, Academic Press, 1978.

[2] F. Alabau-Boussouira, Convexity and weighted intgral inequalities for energy decay rates of nonlinear dissipative hyperbolic systems, Appl. Math. Optim., 51 (2005), 61-105.

[3] V.I. Arnold, Mathematical methods of classical mechanics, Springer-Verlag, New York, 1989.

[4] V. Komornik, Well-posedness and decay estimates for a Petrovsky system by a semigroup approach, Acta Sci. Math. (Szeged), 60 (1995), 451-466.

[5] S. Kouémou-Patcheu, Global exixtence and exponential decay estimates for a dampad quasilinear equation, Comm. Partial Differential Equations, 22 (1997), 2007-2024

[6] A. Guesmia, Existence globale et stabilisation interne non lineaire d'un systeme de Petrovsky, Bell. Belg. Math. Soc., 5 (1998), 583-594.

[7] S. Kouémou-Patcheu, On a Global Solution and Asymptotic Behaviour for the Generalized Damped Extensible Beam Equation, J. Differential Equations, 135 (1997), 299-314.

[8] I. Lasiecka Stabilization of wave and plate-like equation with nonlinear dissipation on the boundary, J. Differential Equations, 79 (1989), 340-381.

[9] S.A. Messaoudi, Global existence and nonexistence in a system of Petrovsky, J.Math Anal. Appl., 265 (2002), 296-308.

[10] M.I. Mustafa and S.A. Messaoudi, General energy decay for a weakly damped wave equation, Commun. Math. Anal., 9 (2010), 1938-1978.

The authors thank the referee for his helpful comments and suggestions.

DOI: $10.24193 /$ mathcluj.2021.2.13 
[11] I. Lasiecka and D. Toundykov, Energy decay rates for the semilinear wave equation with nonlinear localized damping and source terms, Nonlinear Anal., 64 (2006), 1757-1797.

[12] J.L. Lions, Quelques méthodes de résolution des problémes aux limites nonlinéaires, Dunod Gautier-Villars, Paris, 1969.

[13] W.J. Liu and E. Zuazua, Decay rates for dissipative wave equations, Ric. Mat., 48 (1999), 61-75.

Received December 3, 2019

Accepted November 12, 2020
University of Mascara

Mustapha Stambouli, Algeria

E-mail: abdelli.mama@gmail.com

E-mail: mounir.bahlil@univ-mascara.dz

Djillali Liabes University,

Laboratory of Analysis and Control

of Partial Differential Equations

P. O. Box 89, Sidi Bel Abbes 22000, Algeria

E-mail: tayeblakroumbe@yahoo.fr

https://orcid.org/0000-0002-4173-6335

E-mail: abdelli.mama@gmail.com

https://orcid.org/0000-0003-2641-5223

E-mail: louhibi_ben@yahoo.fr

https://orcid.org/0000-0002-4570-2677

E-mail: mounir.bahlil@univ-mascara.dz

https://orcid.org/0000-0002-9688-8897 